\title{
Obesity and hepatocellular carcinoma in patients receiving entecavir for chronic hepatitis $B$
}

\author{
Jaemin Lee ${ }^{1, *}$, Sun Hong Yoo ${ }^{1,2, *}$, Won Sohn ${ }^{1,2}$, Hyung Woo Kim 1 , Yong Sun Choi', Jung Ho Won', Jin Young Heo', \\ Sang Jong Park ${ }^{1,2}$, and Young Min Park ${ }^{1,2}$ \\ 'Department of Internal Medicine, and 'Liver Center, Bundang Jesaeng Hospital, Seongnam, Korea
}

\begin{abstract}
Background/Aims: This study aimed to clarify the effect of obesity on the development of hepatocellular carcinoma (HCC) in chronic hepatitis B (CHB) patients receiving antiviral treatment.

Methods: This study applied a retrospective analysis to a historical cohort in Bundang Jesaeng Hospital. In total, 102 CHB patients were treated with entecavir as an initial treatment for CHB and checked for obesity using a body composition analyzer. Hepatic steatosis was measured semiquantitatively using Hamaguchi's scoring system in ultrasonography. Risk factors for the development of HCC were analyzed, including obesity-related factors (body mass index [BMI], waist circumference [WC], waist-to-hip ratio [WHR], visceral fat area [VFA], and hepatic steatosis).

Results: The median follow-up duration of the patients was 45.2 months (interquartile range: 36.0-58.3 months). The cumulative incidence rates of HCC at 1 year, 3 years, and 5 years were $0 \%, 5.3 \%$, and $9.0 \%$, respectively. Univariable analysis revealed that the risk factors for HCC development were a platelet count of $<120,000 / \mathrm{mm}^{2}$ (hazard ratio $[\mathrm{HR}]=5.21, P=0.031), \mathrm{HBeAg}$ negativity $(\mathrm{HR}=5.61, P=0.039)$, and liver cirrhosis ( $\mathrm{HR}=10.26, P=0.031)$. Multivariable analysis showed that the significant risk factor for HCC development was liver cirrhosis (HR=9.07, $P=0.042$ ). However, none of the obesity-related risk factors were significantly associated with $\mathrm{HCC}: \mathrm{BMI} \geq 25 \mathrm{~kg} / \mathrm{m}^{2}$ ( $\left.\mathrm{HR}=0.90, P=0.894\right), W C \geq 90 \mathrm{~cm}$ (HR=1.10, $P=0.912), W H R \geq 0.9$ (HR=1.94, $P=0.386), V F A \geq 100 \mathrm{~cm}^{2}$ (HR=1.69, $\left.P=0.495\right)$, and hepatic steatosis (HR=0.57, $P=0.602$ ).
\end{abstract}

Conclusions: $\mathrm{HCC}$ development is associated with liver cirrhosis but not obesity-related factors in CHB patients receiving entecavir. (Clin Mol Hepatol 2016;22:339-349)

Keywords: Chronic hepatitis B; Hepatocellular carcinoma; Obesity; Antiviral treatment

\section{INTRODUCTION}

Chronic hepatitis $B(\mathrm{CHB})$ is most common etiology of hepatocellular carcinoma (HCC) worldwide.' The prevention of HCC is important for the patients with CHB. Recent studies show that oral antiviral treatment such as nucleos(t)ide analogue (NA) reduces the development of $\mathrm{HCC}$ in patients with $\mathrm{CHB}^{2-4}$ In particular, high potency NA such as entecavir or tenofovir has little drug resistance as well as prominent viral suppression. Therefore, entecavir or tenofovir is recommended as an initial therapy for chronic

\footnotetext{
Abbreviations:

CHB, chronic hepatitis B; HCC, hepatocellular carcinoma; NA, nucleos(t) ide analogue; CHC, chronic hepatitis C; HBV, hepatitis B virus; AST, aspartate transaminase; $A L T$, alanine transaminase; $H B s A g$, hepatitis $B$ virus surface antigen; $\mathrm{HBeAg}$, hepatitis B virus envelope antigen; APRI, AST to Platelet Ratio Index; FIB-4, fibrosis-4; HDL, high-density lipoprotein; LDL, low-density lipoprotein; BMI, body mass index; VFA, visceral fat area; WC, waist circumference; WHR, waist-to-hip ratio; HR, hazard ratio; SD, standard deviation; $\mathrm{Cl}$, confidence interval.

\section{Corresponding author: Won Sohn}

Department of Internal Medicine, and Liver Center, Bundang Jesaeng Hospital, 20 Seohyeon-ro 180beon-gil, Bundang-gu, Seongnam 13590, Korea

Tel: +82-31-779-0391, Fax: +82-31-779-0164

E-mail: hand1@dreamwiz.com 
hepatitis $B{ }^{5,6}$ However, CHB patients receiving NA still have a higher risk of $\mathrm{HCC}$ incidence than inactive state of CHB patients. ${ }^{7}$ Therefore, it is important to have HCC surveillance and investigate risk factors in CHB patients under NA therapy.

Obesity is an independent risk factor for cancer incidence, ${ }^{8}$ and is associated with the mortality in patients with cancer. ${ }^{9}$ Obesity is closely related to cancer regardless of gender, region, and type of cancer. ${ }^{10} \mathrm{HCC}$ is also associated with obesity. ${ }^{11}$ However, the association between obesity and HCC are not always consistent, and is different according to the underlying liver disease. Non-alcoholic fatty liver disease, which is closely related to obesity, is a cause of HCC. ${ }^{12}$ Obesity is a significant risk factor for HCC incidence in patients with chronic hepatitis $\mathrm{C}(\mathrm{CHC}){ }^{13}$ On the other hand, the relationship between obesity and HCC is not clear in CHB. A large scale Taiwanese cohort study shows that HCC incidence is not related to obesity in CHB while obesity is an independent risk factor for $\mathrm{HCC}$ development in $\mathrm{CHC}^{14}$

Hence, still it is unclear whether obesity increases the risk of HCC in CHB patients, especially for those under NA therapy. To clarify these issues, we investigated several obesity-related variables, and assessed whether this parameters are associated with HCC development in CHB patients on entecavir therapy. In addition, we also assessed whether these obesity-related parameters are associated with hepatitis B viral load, and other clinical endpoints during NA therapy.

\section{PATIENTS AND METHODS}

\section{Study design and patients}

This study was retrospectively conducted from a historical co- hort at Bundang Jesaeng Hospital, Seongnam, Korea. From January 2009 to December 2012, 150 patients were treated with entecavir as an initial treatment for CHB and checked with body composition analyzer (Fig. 1). CHB was defined when hepatitis $B$ virus surface antigen ( $\mathrm{HBsAg}$ ) is positive for at least 6 months. Of these patients, we excluded 48 patients: (i) diagnosed with HCC before starting entecavir ( $n=14$ ); (ii) diagnosed with cholangiocarcinoma before starting entecavir $(n=1)$; (iii) liver transplantation before starting entecavir ( $n=2$ ); (iv) incomplete data on laboratory studies ( $n=13)$; (v) loss of follow-up within 6 months $(n=18)$. Therefore, we finally analyzed 102 patients in this study. The diagnosis of HCC was based on the American Association for the Study of Liver Diseases (AASLD) guidelines. ${ }^{15}$ The criteria for starting antiviral therapy was based on the Korean Association for the Study of the Liver (KASL) guideline: (i) hepatitis B virus (HBV) DNA $\geq 20,000 \mathrm{IU} / \mathrm{mL}$ and serum aspartate transaminase (AST) or alanine transaminase (ALT) level $\geq 2 \times$ upper limit of normal (ULN) in HBV envelope antigen (HBeAg) positive patients, (ii) HBV DNA $\geq 2,000 \mathrm{IU} / \mathrm{mL}$ and serum aminotransferase level $\geq 2 \times U L N$ in $\mathrm{HBeAg}$ negative patients, and (iii) HBV DNA $\geq 2,000 \mathrm{IU} / \mathrm{mL}$ and serum AST or ALT $\geq$ ULN in liver cirrhosis. ${ }^{16}$ This study was approved by the Institutional Review Board of Bundang Jesaeng Hospital (IRB NO: IMH15-03).

\section{Clinical parameters}

We investigated baseline characteristics of the patients: age, gender, total bilirubin, AST, ALT, platelet count, albumin, prothrombin time, ascites, hepatic encephalopathy, presence of HBeAg, HBV DNA level, presence of liver cirrhosis, Child-Pugh classification, AST to Platelet Ratio Index (APRI), fibrosis-4 (FIB-4), total cholesterol, triglyceride, high-density lipoprotein (HDL) cho-

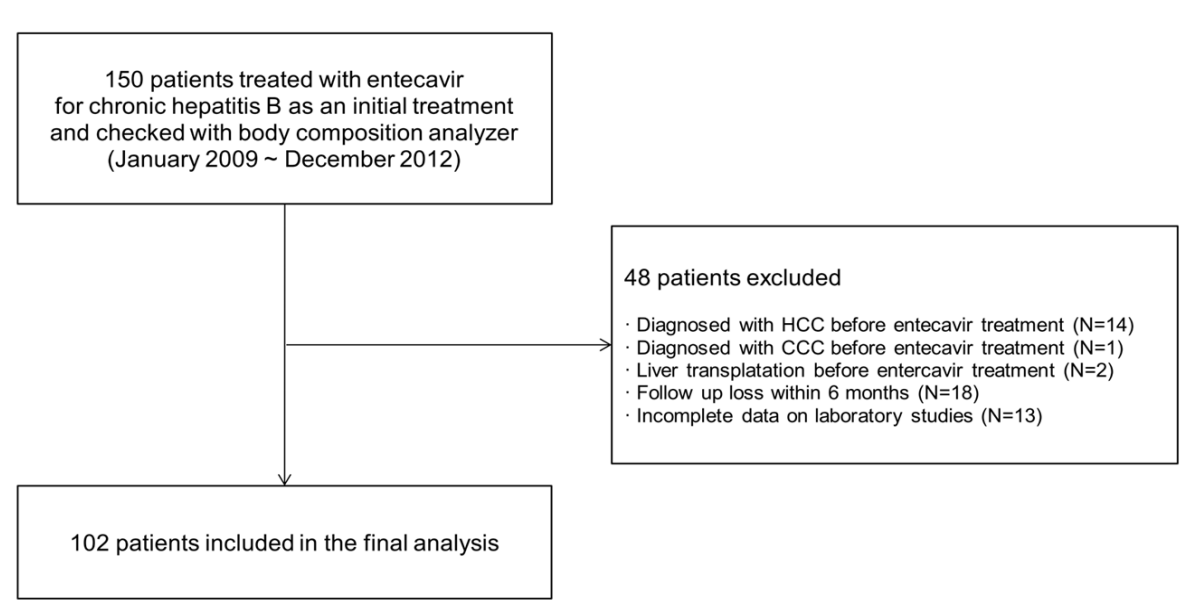

Figure 1. Flow diagram of enrolled patients. HCC, hepatocellular carcinoma; CCC, cholangiocarcinoma. 
lesterol, low-density lipoprotein (LDL), alcohol intake, presence of diabetes mellitus, hypertension, and metabolic syndrome. Serum HBV DNA level was checked by COBAS TaqMan quantitative test for hepatitis B virus (Roche Molecular Systems Inc., Branchburg, NJ, USA). Liver cirrhosis was diagnosed based on ultrasonographic findings. ${ }^{17}$ Significant alcohol consumption is defined as drinking above $210 \mathrm{gram} /$ week for men and above $140 \mathrm{gram} /$ week for women. ${ }^{18}$ Metabolic syndrome was defined by updated National Cholesterol Education Program Adult Treatment Panel III standards. ${ }^{19,20}$

\section{Assessment of obesity and hepatic steatosis}

For evaluating obesity, following variables were checked in this study: body mass index (BMI), waist circumference (WC), waistto-hip ratio (WHR), and visceral fat area (VFA). These variables were measured by electrical bioimpedance analysis and those were measured using IOI-353 Body Composition Analyzer (Jawon Medical Co., Seoul, Korea).

Hepatic steatosis (fatty liver) was evaluated by ultrasonography. Trained hepatologists (YM. Park and SH. Yoo) performed ultrasonography. For this study, ultrasonographic hepatic steatosis was newly assessed by two hepatologists (SH. Yoo and W. Sohn). They reviewed ultrasonographic images of all patients without knowing any clinical information. To assess hepatic steatosis, we used Hamaguchi's ultrasonographic score, from 0 to 6 points (S0-S6) considering bright hepatic echogenicity, hepatorenal echo contrast, deep attenuation and vessel blurring. ${ }^{21}$ Based on this scoring system, mild hepatic steatosis was defined by score 2-3 (S2-S3) and moderate/severe hepatic steatosis was defined by $\geq s$ core 4 $(\geq S 4)$. Sonographic hepatic steatosis was scored based on an agreement by two hepatologists (SH. Yoo and W. Sohn). In case of disagreement, we re-reviewed the sonographic images and determined the score by agreement. Unless the cases are not agreed in spite of re-assessment, we determined the mean value of two scoring measurements as the final result.

\section{Follow-up after starting antiviral treatment}

After starting entecavir, enrolled patients underwent imaging study (abdominal ultrasonography and/or contrast-enhanced multiphase computed tomography) and serum alpha-fetoprotein every 6 months. Magnetic resonance imaging or liver biopsy was additionally used to confirm HCC if necessary. We also assessed disease progression in patients after starting entecavir. Disease progression was defined as the first occurrence one of following events: i) increase by $\geq 2$ points of Child-Pugh score compared to baseline; ii) spontaneous bacterial peritonitis; iii) renal insufficiency; iv) variceal bleeding; v) HCC development; vi) death. ${ }^{2}$ To evaluate the efficacy of entecavir, serum laboratory tests such as serum aminotransferase level, HBeAg, hepatitis B virus enveolope antibody (HBeAb) and hepatitis $B$ virus DNA level were performed every 3 or 6 months.

\section{Assessment of outcomes}

Time to HCC development, risk factors affecting for HCC development, virological response to entecavir, and overall survival were investigated. Also, we evaluated relationship between obesity-related factors and hepatitis B viral load before entecavir treatment. Time to HCC development and disease progression were defined as the duration from an initiation of entecavir to a detection of HCC or the first occurrence one of above disease progression events, respectively. Virological response to entecavir was checked as a proportion of patients with HBV DNA level $<69$ $\mathrm{IU} / \mathrm{mL}$ at 48 weeks and 96 weeks, respectively. Biochemical response to entecavir was checked as a proportion of patients with serum ALT level $<40 \mathrm{IU} / \mathrm{mL}$ at 48 weeks and 96 weeks, respectively. The follow-up period for survival analysis was defined as the duration between an initiation of entecavir and either a development of event or the last visit to outpatient clinic before December 31, 2015.

\section{Statistical analysis}

Categorical variables were presented as frequencies and percentages. Continuous variables were demonstrated as mean value with standard deviation (SD) and median value with interquartile range. We assessed the inter-observer variability of Hamaguchi's score using kappa value ( $\mathrm{k})$. That was interpreted as bellows: 0.01-0.20, slight agreement; 0.21-0.40, fair agreement; 0.41 0.60 , moderate agreement; 0.61-0.80, substantial agreement; 0.81-0.99, almost perfect agreement. ${ }^{22}$ Kaplan-Meier curve was used to calculate the cumulative incidence of HCC and overall survival. Log-rank test was used to compare the incidence of $\mathrm{HCC}$ according to risk factors. Univariable and multivariable Cox proportional hazards model was used to identify the risk factors for the development of HCC. Multivariable analysis was done using a backward conditional stepwise procedure to avoid the multicollinearity. Spearman correlation coefficient $(r)$ was used for investi- 
Table 1. Baseline characteristics of enrolled patients ( $N=102)$

\begin{tabular}{|c|c|}
\hline & Number/mean \pm S.D. \\
\hline Age & $46.4 \pm 11.2$ \\
\hline Women/men (N, \%) & $35 / 67(34 / 66)$ \\
\hline Total bilirubin (mg/dL) & $1.2 \pm 1.0$ \\
\hline AST (U/L) & $196.6 \pm 532.2$ \\
\hline $\operatorname{ALT}(\mathrm{U} / \mathrm{L})$ & $224.9 \pm 440.8$ \\
\hline Albumin (g/dL) & $4.0 \pm 0.4$ \\
\hline Platelet count $\left(\times 10^{3} / \mathrm{mm}^{3}\right)$ & $165.1 \pm 57.3$ \\
\hline Prothrombin time (INR) & $1.1 \pm 0.2$ \\
\hline Ascites (N, \%) & $8(8)$ \\
\hline Hepatic encephalopathy (N, \%) & $0(0)$ \\
\hline HBeAg positivity (N, \%) & $71(70)$ \\
\hline HBV DNA level (IU/mL, median with interquartile range) & $7340040.5(474098.3-138000000)$ \\
\hline Liver cirrhosis (N, \%) & $36(35)$ \\
\hline Child-Pugh class A/B/C (N, \%) & $94 / 6 / 2(92 / 6 / 2)$ \\
\hline APRI & $4.5 \pm 8.2$ \\
\hline FIB-4 & $2.9 \pm 4.3$ \\
\hline Total cholesterol (mg/dL) & $176.6 \pm 32.2$ \\
\hline Triglyceride (mg/dL) & $101.5 \pm 52.4$ \\
\hline HDL cholesterol (mg/dL) & $56.0 \pm 15.9$ \\
\hline LDL cholesterol (mg/dL) & $104.8 \pm 27.2$ \\
\hline Fasting blood glucose (mg/dL) & $96.2 \pm 19.1$ \\
\hline Systolic blood pressure (mg/dL) & $122.1 \pm 14.8$ \\
\hline Diastolic blood pressure (mg/dL) & $76.9 \pm 10.7$ \\
\hline Significant alcohol consumption ${ }^{*}(\mathrm{~N}, \%)$ & $19(19)$ \\
\hline Diabetes mellitus ( $N, \%)$ & $4(4)$ \\
\hline Hypertension (N, \%) & $5(5)$ \\
\hline Body mass index $\left(\mathrm{kg} / \mathrm{m}^{2}\right)$ & $23.6 \pm 3.1$ \\
\hline Waist circumference ${ }^{\dagger}(\mathrm{cm})$ & $82.5 \pm 9.4$ \\
\hline Waist-to-hip ratio $^{\dagger}$ & $0.86 \pm 0.08$ \\
\hline Visceral fat $\operatorname{area}^{\dagger}\left(\mathrm{cm}^{2}\right)$ & $89.1 \pm 40.8$ \\
\hline Metabolic syndrome (N, \%) & $16(16)$ \\
\hline Hepatic steatosis on US: none/mild/moderate or severe ${ }^{\ddagger}(\mathrm{N}, \%)$ & $78 / 19 / 5(76 / 19 / 5)$ \\
\hline
\end{tabular}

S.D., standard deviation; AST, aspartate aminotransferase; ALT, alanine aminotransferase; INR, international normalized ratio; HBeAg, hepatitis B envelope antigen; APRI, AST to Platelet Ratio Index; FIB-4, fibrosis-4; HDL, high-density lipoprotein; LDL, low-density lipoprotein; US, ultrasonography.

*Significant alcohol consumption is defined as drinking above $210 \mathrm{gram} /$ week for men and above $140 \mathrm{gram} /$ week for women.

The variables were measured by electrical impedance analysis.

${ }^{\ddagger}$ Hepatic steatosis was semiquantitatively evaluated using Hamaguchi's scoring system on ultrasonography (0-6): 0-1, no steatosis; 2-3, mild steatosis; $\geq 4$, moderate or severe steatosis

gating the relationship of baseline HBV DNA (before starting entecavir) and obesity associated factors (BMI, WC, WHR, and VFA). All statistical analysis was done using SPSS for windows release
18.0 (SPSS Inc., Chicago, IL, USA). When $P$-value was $<0.05$ in a two-sided test, it was regarded as statistically significant. 


\section{RESULTS}

\section{Baseline characteristics}

Baseline characteristics are shown in Table 1. The median age of patients was 46.4 years and the majority of patients were men (66\%). The mean level of serum ALT was $224.9 \mathrm{lU} / \mathrm{mL}$. HBeAg positivity was observed in 71 patients (70\%). Thirty six patients had cirrhotic patients (35\%). Child-Pugh class of patients was class A in 94 (92\%), class B in $6(6 \%)$, and class C in $2(2 \%)$ patients. The median level of HBV DNA was 7,340,040.5 IU/mL. Diabetes mellitus, hypertension, and metabolic syndrome were observed in $4(4 \%), 5(5 \%)$, and $16(16 \%)$. The median levels of serum fasting glucose, triglyceride, and LDL cholesterol were $96.2,101.5$, and $104.8 \mathrm{mg} / \mathrm{dL}$. The degree of hepatic steatosis none in 78 patients (76\%), mild in 19 patients (19\%), and moderate or severe in 5 patients (5\%). The inter-observer agreement of hepatic steatosis was good ( $\mathrm{K}=0.879,95 \%$ C.I [0.821-0.918]). The mean values of BMI, WC, WHR, and VFA were $23.6 \mathrm{~kg} / \mathrm{m}^{2}$, $82.5 \mathrm{~cm}, 0.86$ and $89.1 \mathrm{~cm}^{2}$.

\section{Relationship between hepatitis B viral load and obesity associated risk factors}

The relationship between baseline HBV DNA level (before starting entecavir) and obesity-related factors (BMI, WC, WHR, and VFA) was demonstrated in Figure 2. There was a significant inverse correlation between HBV DNA level and BMI $(r=-0.208$, $P=0.036), \operatorname{WHR}(r=-0.285, P=0.004)$, and VFA $(r=-0.293$, $P=0.003$ ) (Fig. 2A, 2C, and 2D). Relationship between HBV DNA
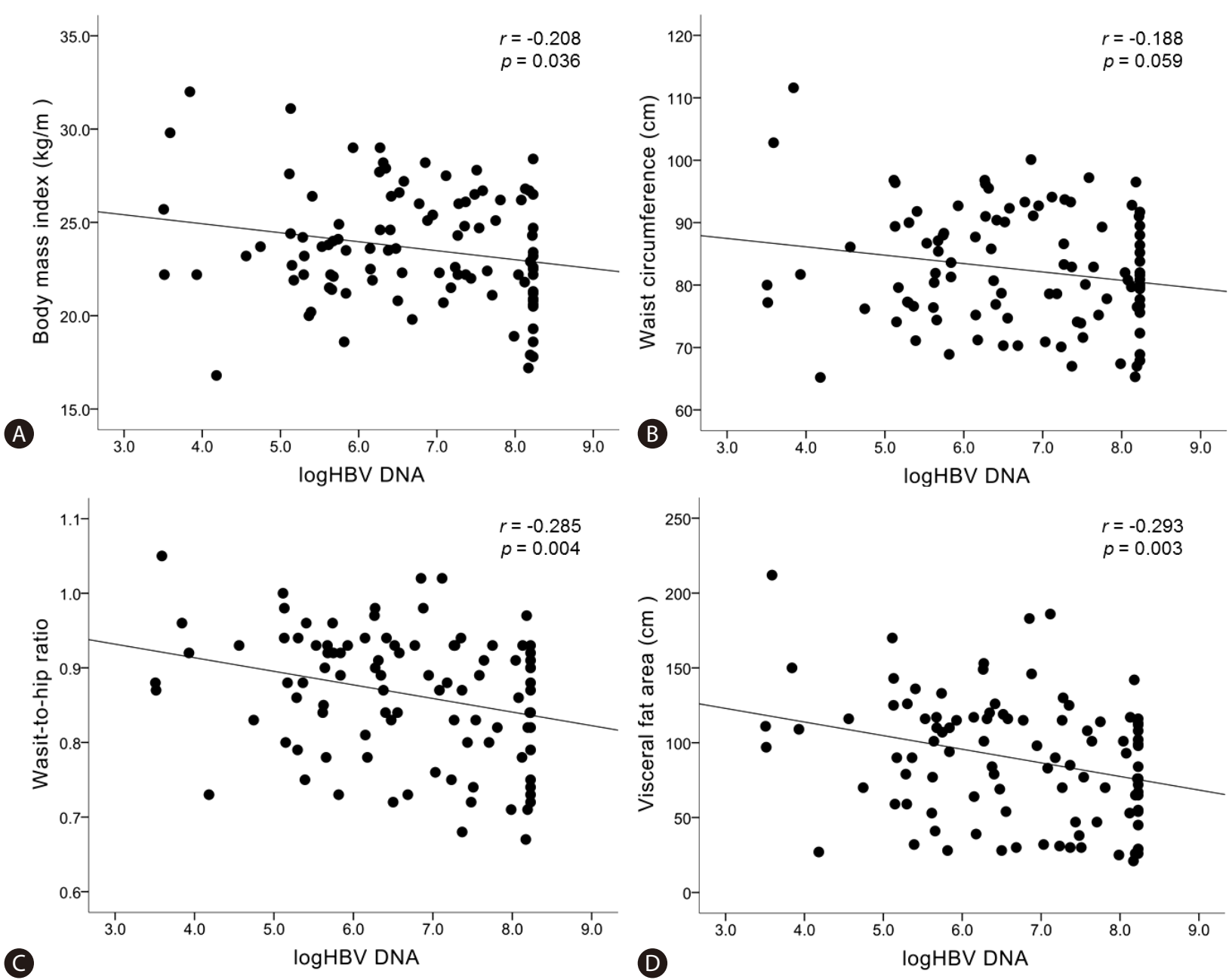

Figure 2. Correlations between hepatitis B viral load and obesity-related factors upon starting entecavir. " $r$ " is the correlation coefficient between $\log _{10} H B V$ DNA and each risk factors. Statistical significance is regarded when $p$-value is less than 0.05 . 
Table 2. Results of univariable and multivariable analyses of risk factors for HCC development in patients treated with entecavir for $\mathrm{CHB}$ ( $\mathrm{N}=102$ )

\begin{tabular}{|c|c|c|c|c|}
\hline & $\begin{array}{c}\text { Univariable HR } \\
(95 \% \mathrm{Cl})\end{array}$ & $P$-value & $\begin{array}{c}\text { Multivariable HR } \\
(95 \% \mathrm{Cl})\end{array}$ & $P$-value \\
\hline Age $\geq 60$ years & $2.48(0.48-12.82)$ & 0.277 & & \\
\hline Men & $1.29(0.25-6.64)$ & 0.763 & & \\
\hline Total bilirubin $\geq 1.2 \mathrm{mg} / \mathrm{dL}$ & $0.98(0.19-5.08)$ & 0.981 & & \\
\hline $\mathrm{AST} \geq 120 \mathrm{U} / \mathrm{L}$ & $0.39(0.47-3.25)$ & 0.384 & & \\
\hline$A L T \geq 120 \mathrm{U} / \mathrm{L}$ & $0.25(0.30-2.06)$ & 0.197 & & \\
\hline Albumin $<4.0 \mathrm{~g} / \mathrm{dL}$ & $3.00(0.67-13.40)$ & 0.151 & & \\
\hline Gamma-glutamyl transpeptidase $\geq 50$ IU/L & $3.84(0.46-31.89)$ & 0.214 & & \\
\hline Platelet count $<120 \times 10^{3} / \mathrm{mm}^{3}$ & $5.21(1.16-23.29)$ & 0.031 & & \\
\hline Ascites & $4.84(0.94-25.09)$ & 0.060 & & \\
\hline HBeAg negativity & $5.61(1.09-28.92)$ & 0.039 & $4.84(0.94-25.05)$ & 0.060 \\
\hline HBV DNA $\geq 1 \times 10^{7} \mathrm{IU} / \mathrm{mL}$ & $0.18(0.02-1.50)$ & 0.113 & & \\
\hline Child-Pugh class B or C & $2.62(0.32-21.81)$ & 0.372 & & \\
\hline Liver cirrhosis & $10.26(1.23-85.50)$ & 0.031 & $9.07(1.09-75.69)$ & 0.042 \\
\hline DM / Dyslipidemia / HTN / MS & $0.28(0.03-2.35)$ & 0.242 & & \\
\hline Body mass index $\geq 25 \mathrm{~kg} / \mathrm{m}^{2}$ & $0.90(0.17-4.62)$ & 0.894 & & \\
\hline Waist circumference $\geq 90 \mathrm{~cm}$ (men) or $\geq 80 \mathrm{~cm}$ (women) & $0.88(0.17-4.53)$ & 0.879 & & \\
\hline Waist-to-hip ratio $\geq 0.9$ & $1.94(0.23-15.87)$ & 0.386 & & \\
\hline Visceral fat area $\geq 100 \mathrm{~cm}^{2}$ & $1.69(0.43-8.71)$ & 0.495 & & \\
\hline Hepatic steatosis on ultrasonography & $0.57(0.07-4.74)$ & 0.602 & & \\
\hline
\end{tabular}

HCC, hepatocellular carcinoma; CHB, chronic hepatitis B; HR, hazard ratio; Cl, confidence interval; AST, aspartate aminotransferase; ALT, alanine aminotransferase; DM, diabetes mellitus; HTN, hypertension; MS, metabolic syndrome.

level and WC was inverse but it did not reach a statistically significance $(r=-0.188, P=0.059)$ (Fig. 2B).

We investigated the change of obesity associated factors after hepatitis B viral load was suppressed thorough antiviral treatment. Of 102 patients, 86 patients were checked with bioelectrical impedance analysis for obesity after hepatitis B viral load was suppressed. There is no significant difference in the change of obesity associated factors when hepatitis $B$ viral load was suppressed: BMI $(23.6 \pm 3.1->23.6 \pm 3.0, P=0.918) ; W C(82.5 \pm$ $9.4->81.9 \pm 8.6, P=0.899) ;$ WHR $(0.86 \pm 0.08->0.87 \pm 0.08$, $P=0.081) ;$ VFA $(89.1 \pm 40.8->90.2 \pm 38.6, P=0.401)$.

\section{$\mathrm{HCC}$ incidence in CHB patients treated with entecavir}

The median follow-up duration of the patients was 45.2 (interquartile range: $36.0-58.3$ ) months. Of 102 patients, HCC development was observed in 7 patients. The cumulative incidence rates of HCC at 1 year, 3 years, and 5 years were $0 \%, 5.3 \%$, and $9.0 \%$, respectively. The mean duration of time to HCC development was
71.5 (95\% Cl: 68.7-74.4) months. The median duration of entecavir administration was 38.0 (interquartile range: 23.6-51.9) months. Of 102 patients, death was observed in 3 patients.

\section{Effect of obesity associated factors on virological response, biochemical response, and $\mathrm{HBeAg}$ seroconversion}

Virological response rates of entecavir were 80\% (76/95) at 48 weeks and $94 \%(79 / 84)$ at 96 weeks. Biochemical response rates of entecavir were $79 \%(75 / 95)$ at 48 weeks and $86 \%(72 / 84)$ at 96 weeks. Drug resistance was detected in one patient. The rate of HBeAg seroconversion was 38\% (27/71).

The differences in virological response, biochemical response, and HBeAg seroconversion according to obesity associated factors were demonstrated in Figure 3. There was no statistical difference in virological response at 96 weeks and HBeAg seroconversion according to obesity associated factors (BMI, WC, WHR, VFA, and hepatic steatosis) $(P>0.05)$. On the other hand, bio- 


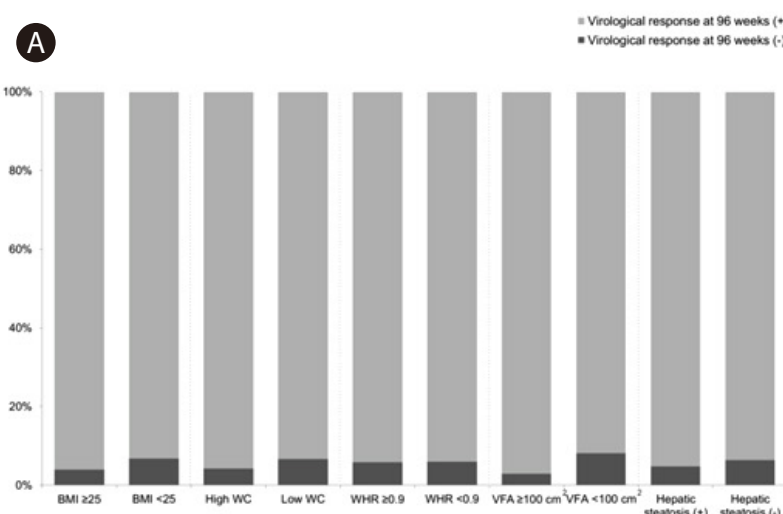

B

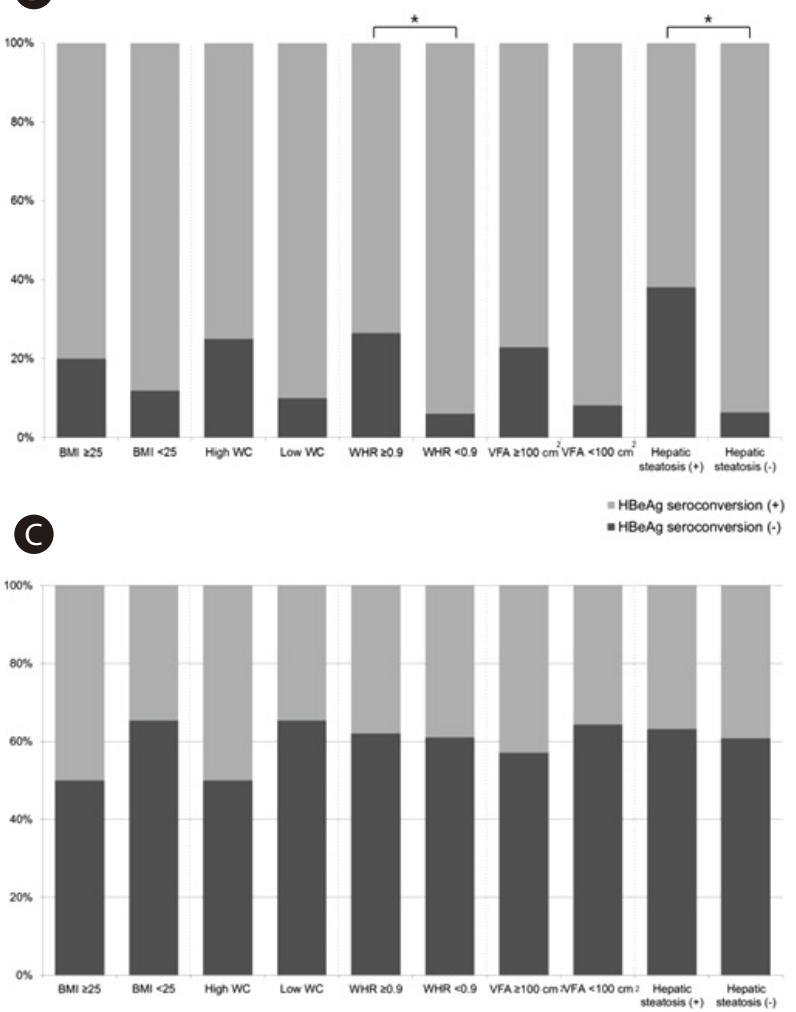

Figure 3. Differences in virological response at 96 weeks (A), biochemical response at 96 weeks (B), and HBeAg seroconversion (C) in CHB patients treated with entecavir. BMl, body mass index; WHR, waist-hip-ratio; VFA, visceral fat area; $C H B$, chronic hepatitis $B$; $H B e A g$, hepatitis $B$ virus envelope antigen. ${ }^{*}$ Statistical significance is regarded when $P$-value is less than 0.05

chemical response to entecavir (ALT $<40 \mathrm{U} / \mathrm{L}$ at 96 weeks) was significantly worse in patients with WHR $\geq 0.9$ than in those with WHR $<0.9$ (non-responder: $26.5 \%$ vs. $6.0 \%, P=0.012$ ). Also, patients with hepatic steatosis has worse biochemical response at 96 weeks than those without hepatic steatosis (non-responder: $38.1 \%$ vs. $6.3 \%, P=0.001)$.

\section{Risk factors for HCC development in CHB patients treated with entecavir}

Risk factors for HCC development were shown in Table 2. Univariable analysis revealed that the risk factors for HCC development were a platelet count of $<120,000 / \mathrm{mm}^{3}$ (HR 5.21, $P=0.031)$, HBeAg negativity (HR 5.61, $P=0.039$ ), and liver cirrhosis (HR 10.26, $P=0.031$ ). However, none of obesity-related risk factors were significantly associated with HCC development in CHB patients treated with entecavir: BMI $\geq 25 \mathrm{~kg} / \mathrm{m}^{2}$ (HR 0.90, $P=0.894), W C \geq 90 \mathrm{~cm}(\mathrm{HR} 1.10, P=0.912), W H R \geq 0.9$ (HR 1.94, $P=0.386), V F A \geq 100 \mathrm{~cm}^{2}$ (HR 1.69, $\left.P=0.495\right)$, and hepatic steatosis (HR 0.57, $P=0.602$ ). Multivariable analysis showed that the significant risk factor for HCC development was liver cirrhosis (HR 9.07, $P=0.042$ ). HBeAg negativity was associated with HCC development, but it didn't reach a statistical significance (HR 4.84, $P=0.06)$.

We compared the difference of HCC incidence according to risk factors (Fig. 4). Cumulative incidence rates of HCC at 1 year, 3 years, and 5 years were $0 \%, 1.9 \%$ and $1.9 \%$, respectively, in noncirrhotic patients and $0 \%, 11.4 \%$, and $19.1 \%$, respectively, in cirrhotic patients (Fig. 4A). The mean durations of time to HCC development were 74.7 (95\% Cl: 73.0-76.3) and 60.8 (95\% Cl: 55.4-66.2) months in non-cirrhotic and cirrhotic patients, respectively. HCC incidence was significantly different according to the presence of liver cirrhosis $(P=0.008)$. However, HCC incidence was not significantly different according to obesity-related risk factors such as BMI (Fig. 4B), presence of diabetes mellitus, dyslipidemia, hypertension, metabolic syndrome (Fig. 4C), WHR (Fig. 4D), VFA (Fig. 4E), and hepatic steatosis (Fig. 4F).

\section{Risk factors for disease progression in CHB patients treated with entecavir}

Of 102 patients, 11 patients were regarded as disease progression after antiviral treatment: increase by $\geq 2$ points of $C P$ score $(n=1)$; SBP $(n=1)$; renal insufficiency $(n=1)$; variceal bleeding $(n=1)$; HCC $(n=7)$; death $(n=3)$ - some patients have experienced more than 2 events. The median duration of time to disease progression was 67.8 (95\% Cl: 63.2-72.4) months. Risk factors for disease progression were demonstrated in Table 3. Univariable analysis indicated that the risk factors for disease progression were a platelet count of $<120,000 / \mathrm{mm}^{3}$ (HR 5.90, $P=0.005$ ), HBV DNA level $\geq 1 \times 10^{7} \mathrm{IU} / \mathrm{mL}$ (HR 0.09, $\left.P=0.022\right), \mathrm{HBeAg}$ negativity (HR 3.59, $P=0.048$ ), and liver cirrhosis (HR 4.46, $P=0.027$ ). However, 
Table 3. Results of univariable and multivariable analyses of risk factors for disease progression in patients treated with entecavir for $\mathrm{CHB}$ ( $\mathrm{N}=102)$

\begin{tabular}{|c|c|c|c|c|}
\hline & $\begin{array}{c}\text { Univariable HR } \\
(95 \% \mathrm{Cl})\end{array}$ & $P$-value & $\begin{array}{c}\text { Multivariable HR } \\
(95 \% \mathrm{CI})\end{array}$ & $P$-value \\
\hline Age $\geq 60$ years & $2.06(0.53-7.95)$ & 0.294 & & \\
\hline Men & $1.29(0.33-5.01)$ & 0.709 & & \\
\hline Total bilirubin $\geq 1.2 \mathrm{mg} / \mathrm{dL}$ & $1.19(0.35-4.10)$ & 0.779 & & \\
\hline $\mathrm{AST} \geq 120 \mathrm{U} / \mathrm{L}$ & $0.43(0.09-2.07)$ & 0.291 & & \\
\hline$A L T \geq 120 \mathrm{U} / \mathrm{L}$ & $0.32(0.07-1.50)$ & 0.150 & & \\
\hline Albumin $<4.0 \mathrm{~g} / \mathrm{dL}$ & $1.90(0.58-6.25)$ & 0.291 & & \\
\hline Gamma-glutamyl transpeptidase $\geq 50$ IU/L & $2.91(0.63-13.50)$ & 0.172 & & \\
\hline Platelet count $<120 \times 10^{3} / \mathrm{mm}^{3}$ & $5.90(1.72-20.26)$ & 0.005 & $4.06(1.14-14.49)$ & 0.031 \\
\hline Ascites & $3.19(0.81-12.57)$ & 0.098 & & \\
\hline HBeAg negativity & $3.59(1.01-12.74)$ & 0.048 & & \\
\hline HBV DNA $\geq 1 \times 10^{7} \mathrm{IU} / \mathrm{mL}$ & $0.09(0.01-0.71)$ & 0.022 & $0.13(0.02-1.05)$ & 0.055 \\
\hline Child-Pugh class B or C & $1.89(0.39-9.22)$ & 0.431 & & \\
\hline Liver cirrhosis & $4.46(1.18-16.87)$ & 0.027 & & \\
\hline DM / Dyslipidemia / HTN / MS & $0.39(0.09-1.82)$ & 0.233 & & \\
\hline Body mass index $\geq 25 \mathrm{~kg} / \mathrm{m}^{2}$ & $0.98(0.25-3.80)$ & 0.978 & & \\
\hline Waist circumference $\geq 90 \mathrm{~cm}$ (men) or $\geq 80 \mathrm{~cm}$ (women) & $0.95(0.25-3.69)$ & 0.945 & & \\
\hline Waist-to-hip ratio $\geq 0.9$ & $2.47(0.69-8.77)$ & 0.164 & & \\
\hline Visceral fat area $\geq 100 \mathrm{~cm}^{2}$ & $2.12(0.60-7.52)$ & 0.245 & & \\
\hline Hepatic steatosis on ultrasonography & $0.85(0.18-4.03)$ & 0.840 & & \\
\hline
\end{tabular}

${ }^{*} \mathrm{CHB}$, chronic hepatitis B; HR, hazard ratio; Cl, confidence interval; DM, diabetes mellitus; HTN, hypertension; MS, metabolic syndrome.

none of obesity-related risk factors were significantly associated with disease progression in CHB patients treated with entecavir: BMI $\geq 25 \mathrm{~kg} / \mathrm{m}^{2}$ (HR 0.98, $P=0.978$ ), WC $\geq 90 \mathrm{~cm}$ (HR 0.95, $P=0.945$ ), WHR $\geq 0.9$ (HR 2.47, $P=0.164$ ), VFA $\geq 100 \mathrm{~cm}^{2}$ (HR 2.12, $P=0.245$ ), and hepatic steatosis (HR 0.85, $P=0.840$ ). Multivariable analysis indicated that the significant risk factor for disease progression was a platelet count of $<120,000 / \mathrm{mm}^{3}$ (HR 4.06, $P=0.031)$. HBV DNA level $\geq 1 \times 10^{7} \mathrm{IU} / \mathrm{mL}$ was associated with low occurrence of disease progression, but it didn't reach a statistical significance (HR 0.13, $P=0.055$ ).

\section{DISCUSSION}

The present study was conducted to clarify the effect of obesityrelated factors (BMI, WC, WHR, VFA, and hepatic steatosis) on HCC development in CHB patients receiving entecavir. In our study, cirrhosis was an independent risk factor for HCC development while none of the obesity-related factors were associated with HCC risk. The obesity-related factors in CHB patients receiv- ing entecavir were not associated with disease progression, defined by several clinical endpoints as well. The obesity-related factors were inversely associated with HBV DNA levels and biochemical response, but the virological response did not differ.

Hepatitis B virus load is closely associated with HCC risk in CHB patients. ${ }^{23}$ Hence, in order to investigate the effect of obesity on HCC development, it is crucial to include homogeneous population who could achieve and maintain viral suppression by NA during follow-up. In this aspect, we included only those using entecavir therapy, which are highly effective in suppressing viral replication without developing resistance. In this study, the virological response rate was $80 \%$ at 48 weeks and $94 \%$ at 96 weeks, and only one patient developed resistance, giving us good opportunities to investigate impact of obesity-related factors on HCC.

For $\mathrm{CHC}$, obesity is an established risk factor for poorer outcome. However, conflicting results are available for CHB. Obesity is significantly associated with HCC in CHC. High BMI $\left(>25 \mathrm{~kg} / \mathrm{m}^{2}\right)$ is an independent risk factor for $\mathrm{HCC}$ development in $\mathrm{CHC}^{24}$ Obesity is related to HCC recurrence and liver-related complication in 

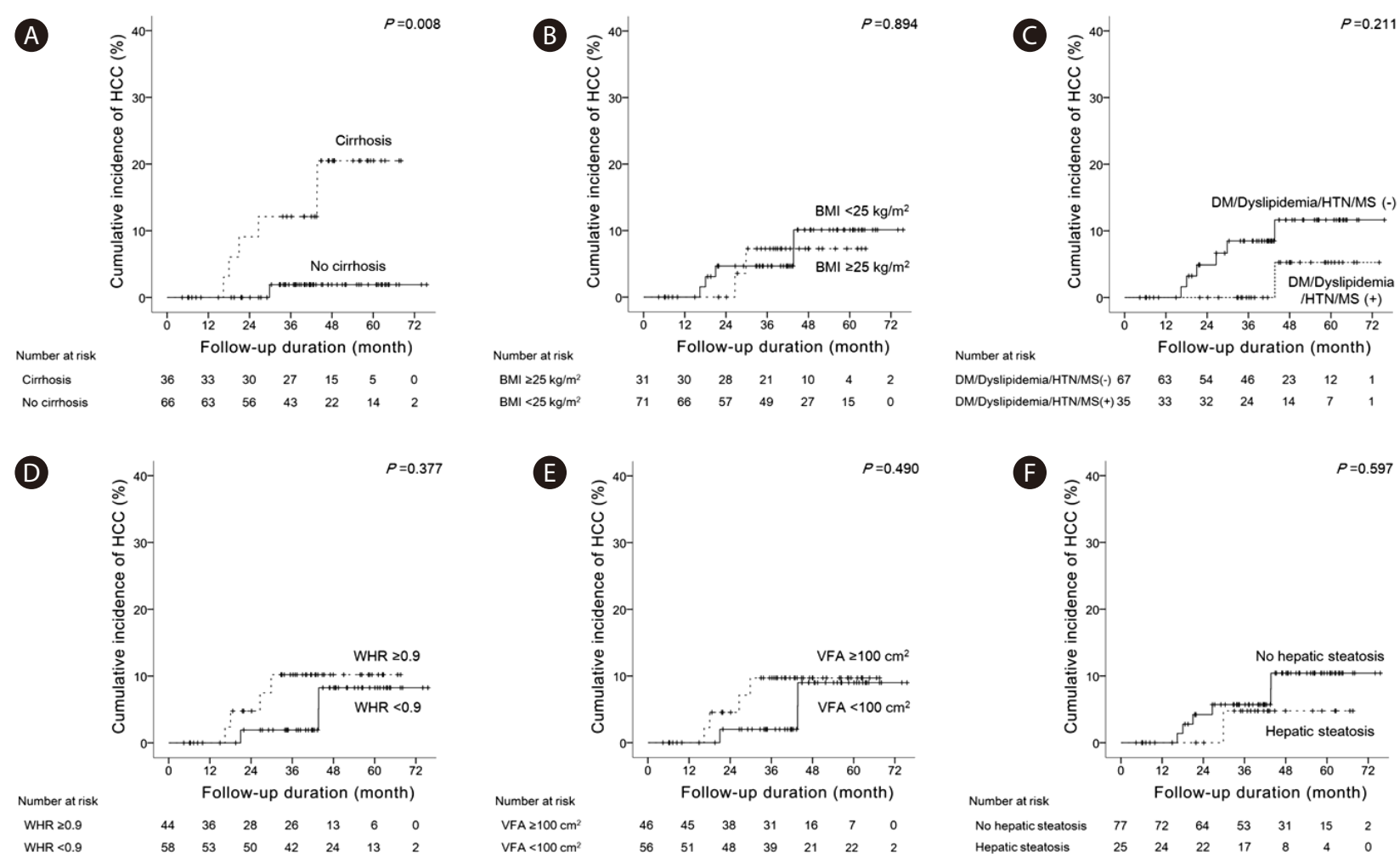

Figure 4. Differences in HCC development according to cirrhosis (A), BMI (B), diabetes mellitus/dyslipidemia/hypertension/metabolic syndrome (C), WHR (D), VFA (E), and hepatic steatosis (F) in CHB patients treated with entecavir. HCC, hepatocellular carcinoma; BMI, body mass index; DM, diabetes mellitus; HTN, hypertension; MS, metabolic syndrome; WHR, waist-hip-ratio; VFA, visceral fat area; CHB, chronic hepatitis B.

CHC patients receiving liver transplantation. ${ }^{25}$ On the other hand, obesity is not a risk factor for HCC development in CHB patents. ${ }^{14}$ Also, obesity is not associated with mortality in patients treated with surgical resection for HBV-related HCC. ${ }^{26}$ In our study, none of the obesity related parameters (BMI, WC, WHR, and VFA) were associated with HCC or disease progression in CHB patients under entecavir therapy. Some studies showed that metabolic syndrome or insulin metabolism increases the risk of liver cirrhosis or HCC in $\mathrm{CHB}^{27,28}$ Large-scaled case-control studies indicated that the risk of HCC development is 2-4 folds higher with type 2 diabetes than without it. ${ }^{29-31} \mathrm{~A}$ recent Taiwanese study showed that new onset diabetes is associated with increased risk of HCC in chronic hepatitis $B .^{32}$ However, Wang et al. showed that diabetes mellitus is an independent risk factor for $\mathrm{HCC}$ in CHC but not in CHB. ${ }^{33}$ Our study did not show that diabetes is the risk factor for HCC development in chronic hepatitis B. In our study, none of the obesity related parameters (BMI, WC, WHR, and VFA) were associated with HCC or disease progression in CHB patients under entecavir therapy. Our data has a merit, as we included homogeneous population under potent NA therapy, and found that obesity-related factors are not risk factors for HCC or disease progression.
In this study, we obesity associated factors had no impact on virological response and HBeAg seroconversion, while poor biochemical response was observed for patients with increased WHR and hepatic steatosis. Consistent to this study, Cindoruk et al. reported no effect of hepatic steatosis on the treatment outcome in $\mathrm{CHB}^{34}$ Furthermore, some studies indicated that there is an inverse relationship between HBV and obesity associated factors. The prevalence of hepatic steatosis and metabolic syndrome is lower in patents with CHB than control group. ${ }^{35,36}$ Machado et al. ${ }^{37}$ showed that HBV DNA level is negatively associated with hepatic steatosis. In our study, here was a significantly inverse relationship between HBV DNA level and obesity-related factors (BMI, WHR, and VFA). Machado et al. suggested that HBV may have a preventing effect for the development of obesity related disorder. ${ }^{37}$ However, it is difficult to address the clinical significance of the inverse relationship between hepatitis B virus load and obesity associated factors because there is no definite evidence of a biological mechanism or interaction between hepatitis $B$ virus and obesity.

This study has several limitations. First, our study can't evaluate insulin resistance such as homeostatic model assessment because 
serum insulin level was not checked. However, we investigated other obesity-related factors such as serum glucose, lipid profile, diabetes mellitus, and metabolic syndrome. All patients were checked with body composition analyzer for obesity. Thus, we assessed VFA as well as BMI and WHR. Second, the quantitative evaluation of hepatic steatosis was not done because liver biopsy was performed in 5 patients. However, we made an effort to evaluate hepatic steatosis semi-quantitatively using the Hamaguchi's scoring system in ultrasonography. However, there was a good inter-observer agreement $(\mathrm{K}=0.879)$ for the evaluation of hepatic steatosis. Finally, this study included small number of sample size and clinical outcomes (HCC or disease progression). Therefore, the statistical power might be rather low to verify our hypothesis. Also, our limitation is that this study was conducted by a retrospective approach. Further prospective studies with enough sample size should be needed to clarify the effect of obesity on HCC development in patients treated with antiviral treatment for CHB.

In conclusion, obesity-related factors were not associated with HCC or disease progression in CHB patients receiving entecavir. The potential role of obesity-related factors warrants further validation in CHB patients under NA therapy

\section{Conflicts of Interest}

The authors have no conflicts to disclose.

\section{REFERENCES}

1. Tsukuma H, Hiyama T, Tanaka S, Nakao M, Yabuuchi T, Kitamura T, et al. Risk factors for hepatocellular carcinoma among patients with chronic liver disease. N Engl J Med 1993;328:1797-1801.

2. Liaw YF, Sung JJ, Chow WC, Farrell G, Lee CZ, Yuen H, et al. Lamivudine for patients with chronic hepatitis $B$ and advanced liver disease. N Engl J Med 2004;351:1521-1531.

3. Hosaka T, Suzuki F, Kobayashi M, Seko Y, Kawamura Y, Sezaki H, et al. Long-term entecavir treatment reduces hepatocellular carcinoma incidence in patients with hepatitis B virus infection. Hepatology 2013;58:98-107.

4. Lim YS, Han S, Heo NY, Shim JH, Lee HC, Suh DJ. Mortality, liver transplantation, and hepatocellular carcinoma among patients with chronic hepatitis B treated with entecavir vs lamivudine. Gastroenterology 2014;147:152-161.

5. European Association For The Study Of The Liver. EASL clinical practice guidelines: management of chronic hepatitis B virus infection. J Hepatol 2012;57:167-185.
6. Terrault NA, Bzowej NH, Chang KM, Hwang JP, Jonas MM, Murad MH. AASLD guidelines for treatment of chronic hepatitis B. Hepatology 2016;63:261-283.

7. Cho JY, Paik YH, Sohn W, Cho HC, Gwak GY, Choi MS, et al. Patients with chronic hepatitis B treated with oral antiviral therapy retain a higher risk for HCC compared with patients with inactive stage disease. Gut 2014;63:1943-1950.

8. Renehan AG, Tyson M, Egger M, Heller RF, Zwahlen M. Body-mass index and incidence of cancer: a systematic review and meta-analysis of prospective observational studies. Lancet 2008;371:569-578.

9. Calle EE, Rodriguez C, Walker-Thurmond K, Thun MJ. Overweight, obesity, and mortality from cancer in a prospectively studied cohort of U.S. adults. N Engl J Med 2003;348:1625-1638.

10. Goodwin PJ, Stambolic V. Impact of the obesity epidemic on cancer. Annu Rev Med 2015;66:281-296.

11. Saunders D, Seidel D, Allison M, Lyratzopoulos G. Systematic review: the association between obesity and hepatocellular carcinoma - epidemiological evidence. Aliment Pharmacol Ther 2010;31:1051-1063.

12. Michelotti GA, Machado MV, Diehl AM. NAFLD, NASH and liver cancer. Nat Rev Gastroenterol Hepatol 2013;10:656-665.

13. Ohki T, Tateishi R, Sato T, Masuzaki R, Imamura J, Goto $T$, et al. Obesity is an independent risk factor for hepatocellular carcinoma development in chronic hepatitis C patients. Clin Gastroenterol Hepatol 2008;6:459-464.

14. Chen CL, Yang HI, Yang WS, Liu CJ, Chen PJ, You SL, et al. Metabolic factors and risk of hepatocellular carcinoma by chronic hepatitis B/C infection: a follow-up study in Taiwan. Gastroenterology 2008;135:111-121

15. Bruix J, Sherman M, Practice Guidelines Committee. American Association for the Study of Liver Diseases. Management of hepatocellular carcinoma. Hepatology 2005;42:1208-1236.

16. Korean Association for the Study of the Liver. KASL Clinical Practice Guidelines: Management of chronic hepatitis B. Clin Mol Hepatol 2012:18:109-162.

17. Nishiura T, Watanabe H, Ito M, Matsuoka Y, Yano K, Daikoku M, et al. Ultrasound evaluation of the fibrosis stage in chronic liver disease by the simultaneous use of low and high frequency probes. $\mathrm{Br}$ J Radiol 2005;78:189-197.

18. Chalasani N, Younossi Z, Lavine JE, Diehl AM, Brunt EM, Cusi K, et al. The diagnosis and management of non-alcoholic fatty liver disease: practice Guideline by the American Association for the Study of Liver Diseases, American College of Gastroenterology, and the American Gastroenterological Association. Hepatology 2012;55:2005-2023.

19. Expert Panel on Detection E, Treatment of High Blood Cholesterol in A. Executive Summary of The Third Report of The National Cholesterol Education Program (NCEP) Expert Panel on Detection, Evaluation, And Treatment of High Blood Cholesterol In Adults (Adult 
Treatment Panel III). JAMA 2001;285:2486-2497.

20. Grundy SM, Brewer HB Jr, Cleeman JI, Smith SC Jr, Lenfant C, American Heart A, et al. Definition of metabolic syndrome: Report of the National Heart, Lung, and Blood Institute/American Heart Association conference on scientific issues related to definition. Circulation 2004;109:433-438.

21. Hamaguchi $M$, Kojima $T$, Itoh $Y$, Harano $Y$, Fujii K, Nakajima $T$, et al. The severity of ultrasonographic findings in nonalcoholic fatty liver disease reflects the metabolic syndrome and visceral fat accumulation. Am J Gastroenterol 2007;102:2708-2715.

22. Viera AJ, Garrett JM. Understanding interobserver agreement: the kappa statistic. Fam Med 2005;37:360-363.

23. Chen CJ, Yang HI, Su J, Jen CL, You SL, Lu SN, et al. Risk of hepatocellular carcinoma across a biological gradient of serum hepatitis $B$ virus DNA level. JAMA 2006;295:65-73.

24. Ohki T, Tateishi R, Shiina S, Goto E, Sato T, Nakagawa H, et al. Visceral fat accumulation is an independent risk factor for hepatocellular carcinoma recurrence after curative treatment in patients with suspected NASH. Gut 2009;58:839-844.

25. Mathur A, Franco ES, Leone JP, Osman-Mohamed H, Rojas H, Kemmer $\mathrm{N}$, et al. Obesity portends increased morbidity and earlier recurrence following liver transplantation for hepatocellular carcinoma. HPB (Oxford) 2013;15:504-510.

26. Wang $H$, Yang J, Zhang $X$, Yan L, Yang J. Liver resection in hepatitis B-related hepatocellular carcinoma: clinical outcomes and safety in overweight and obese patients. PLoS One 2014;9:e99281.

27. Wong GL, Wong VW, Choi PC, Chan AW, Chim AM, Yiu KK, et al. Metabolic syndrome increases the risk of liver cirrhosis in chronic hepatitis B. Gut 2009;58:111-117.

28. Chao LT, Wu CF, Sung FY, Lin CL, Liu CJ, Huang CJ, et al. Insulin, glucose and hepatocellular carcinoma risk in male hepatitis $\mathrm{B}$ carriers: results from 17-year follow-up of a population-based cohort. Carcinogenesis 2011;32:876-881.
29. Adami HO, Chow WH, Nyren O, Berne C, Linet MS, Ekbom A, et al. Excess risk of primary liver cancer in patients with diabetes mellitus. J Natl Cancer Inst 1996;88:1472-1477.

30. Wideroff L, Gridley G, Mellemkjaer L, Chow WH, Linet M, Keehn $\mathrm{S}$, et al. Cancer incidence in a population-based cohort of patients hospitalized with diabetes mellitus in Denmark. J Natl Cancer Inst 1997;89:1360-1365.

31. El-Serag HB, Tran T, Everhart JE. Diabetes increases the risk of chronic liver disease and hepatocellular carcinoma. Gastroenterology 2004;126:460-468.

32. Fu SC, Huang YW, Wang TC, Hu JT, Chen DS, Yang SS. Increased risk of hepatocellular carcinoma in chronic hepatitis B patients with new onset diabetes: a nationwide cohort study. Aliment Pharmacol Ther 2015:41:1200-1209.

33. Wang CS, Yao WJ, Chang TT, Wang ST, Chou P. The impact of type 2 diabetes on the development of hepatocellular carcinoma in different viral hepatitis statuses. Cancer Epidemiol Biomarkers Prev 2009;18:2054-2060.

34. Cindoruk M, Karakan T, Unal S. Hepatic steatosis has no impact on the outcome of treatment in patients with chronic hepatitis B infection. J Clin Gastroenterol 2007;41:513-517.

35. Wong VW, Wong GL, Chu WC, Chim AM, Ong A, Yeung DK, et al. Hepatitis B virus infection and fatty liver in the general population. J Hepatol 2012;56:533-540.

36. Cheng YL, Wang YJ, Kao WY, Chen PH, Huo TI, Huang YH, et al. Inverse association between hepatitis $B$ virus infection and fatty liver disease: a large-scale study in populations seeking for check-up. PLoS One 2013;8:e72049.

37. Machado MV, Oliveira AG, Cortez-Pinto H. Hepatic steatosis in hepatitis $B$ virus infected patients: meta-analysis of risk factors and comparison with hepatitis C infected patients. J Gastroenterol Hepatol 2011;26:1361-1367. 